\title{
Scaling Back and Finding Flexibility: Gender Differences in Parents' Strategies to Manage Work-Family Conflict
}

Studies show that fathers report work-family conflict levels comparable to mothers. The authors examine gender differences in work-related strategies used to ease such conflicts. The authors also test whether the presence of young children at home shapes parents' use of different strategies. They address these focal questions using panel data from the Canadian Work, Stress, and Health study $(\mathrm{N}=306$ fathers, 474 mothers). The authors find that mothers with young children are more likely to scale back on work demands when compared with fathers with young children, but mothers and fathers with older children are equally likely to pursue these strategies. Furthermore, women with young children and men with older children are more likely to seek increased schedule control as a result of work-family conflict when compared with their parent counterparts. The authors situate these findings in the vast literature on the consequences of work-family conflict.

Department of Sociology, McMaster University, 1280 Main Street West, Hamilton, ON, L8S 4M4, Canada (myoung@mcmaster.ca).

*Department of Sociology, University of Toronto, 725 Spadina Avenue, Toronto, ON, M5S 2J4, Canada.

Key Words: employment, family well-being, gender, women, work, work-family issues.
Work-family conflict is considered a modern and prevalent role stressor, yet it is traditionally characterized and even trivialized as the "professional woman's" problem (Spain \& Bianchi, 1996; Williams, 2000). Popular book titles, such as Professor Mommy and Mama PhD, contribute to these perceptions (Connelly \& Ghodsee, 2011; Evans \& Grant, 2008), along with media publications such as Anne-Marie Slaughter's (2012) Atlantic opinion piece titled "Why Women Still Can't Have It All." Exclusive focus on elite career women has hindered our understanding of gender differences in the experience and resolution of work-family conflict-particularly in reference to work-related coping strategies to achieve balance, such as scaling back on paid work, transitioning to less demanding jobs, or opting out of the labor force entirely.

Research documenting the use of such strategies often relies on small samples of professional or executive women that do not capture the broader experiences of women in the labor force or make adequate gender comparisons (Blair-Loy, 2003; Landivar, 2014; Stone, 2007; Sweezy \& Jones, 2012; for exceptions, see also Carr, 2002; Maume, 2006; Reddick, Rochlen, Grasso, Reilly, \& Spikes, 2012; Vanderweyer \& Glorieux, 2008). Several European studies more adequately reflect men's and women's nuanced work-family situations across a myriad 
of occupations (Anxo et al., 2011; Craig \& Mullan, 2010; Vanderweyer \& Glorieux, 2008). There is limited evidence from representative studies of North America, especially in the Canadian population. Ours is among the first that we know of to explore these associations with representative Canadian survey data (for some American exceptions, see Carr, 2002; Maume, 2006; Mennino \& Brayfield, 2002; Sayer, 2005). Work-family conflict is considered bidirectional, where work intrudes on family time and expectations (work-to-family conflict) versus the opposite (family-to-work conflict). For our purposes, we focus on work-to-family conflict only (referenced as "work-family conflict" throughout), with the assumption that work-related strategies will most likely be adopted to assuage this particular direction of conflict when compared with family-to-work conflict, which may prompt changes in the household. A focus on family-to-work conflict is therefore beyond our study's scope.

Our contribution of a population-based gender comparison is timely. Recent studies show that men report levels of work-family conflict comparable to their female counterparts (Aryee, Srinivas, \& Tan, 2005; Aumann, Galinsky, \& Matos, 2011; Nomaguchi, 2009). These trends may reflect women's increased role in the labor market coupled with their changing experiences of work-family conflict or fathers' increased investment in the family sphere, as suggested by research on "intimate fatherhood" and "men who mother" (Bianchi et al., 2012; Dermott, 2008; Doucet, 2006; Williams, 2000). Despite the underlying reason for the closing gender gap in work-family conflict during the past decade, we are primarily interested in whether men and women are adopting (either by choice or constraint) similar work-related strategies as women to deal with conflicting work and family experiences. To address this question, we use two-wave panel data from the 2011-2013 Canadian Work, Stress, and Health study (Schieman, 2011), a national study including key measures on work-family conflict and work-related strategies. Focusing on married and cohabiting respondents only with at least one child at Wave 1, we ask the following: Does work-family conflict prompt individuals to modify their current work arrangements? Do mothers and fathers differ in the implementation of these strategies?

We further consider whether these patterns depend on the presence of young children in the household. Work-family conflict experiences and strategies vary among parents with and without young children (Allen \& Finkelstein, 2014; Becker \& Moen, 1999). Young children require additional time and energy when compared with older children, which may exacerbate work-family conflict-especially among mothers, who bear the lion's share of child care (Bianchi et al., 2006; Marshall, 2011). Parents with younger children may pursue different strategies when compared with those with older children to help cope with the demands of younger children.

We also address the following final question: Does the presence of young children at home further condition our proposed associations among work-family conflict, gender, and work-related coping strategies? In the following sections, we outline our hypotheses by first discussing women's experiences of work-family conflict and their strategies to reduce it. We then discuss men's experiences and whether men adopt similar strategies as women, based on traditional or egalitarian gender norms. Finally, we consider how the gendered adoption of such strategies in response to work-family conflict may vary for respondents with and without young children.

\section{LITERATURE REVIEW}

\section{Women's Experiences of Work-Family Conflict and Adopted Work-Related Strategies}

A majority of women simultaneously combine work and family, and many feel that they successfully do so (Aumann et al., 2011; Young, Schieman, \& Milkie, 2014). Approximately $70 \%$ of American and Canadian mothers are in the paid labor force-a figure that has grown in recent years (Statistics Canada, 2011; U.S. Census Bureau, 2011). Despite these gains, women still face challenges when combining work and family obligations, especially if they have young children (Allen \& Finkelstein, 2014). The inability for women to achieve balance between these spheres is largely a product of state regulations, labor market demands and discrimination, organizational policies, and individual-level demands (Moen, 2015). Persistent inequality and the mismatch in women's work and family demands have been referenced as the "unfinished" or "stalled" gender revolution (England, 2010; Gerson, 2010). The incongruence between work and family demands facilitates what is 
often called "work-family conflict"-a common and serious mental health risk (Bellavia \& Frone, 2005). Recent studies report that more than $70 \%$ of North Americans experience some interference between work and family (Bond et al., 2003; Schieman et al., 2009) — and many studies demonstrate the negative health consequences (Glavin, Schieman, \& Reid, 2011; Wheaton et al., 2012; Young et al., 2014).

Several theories explain the processes of work-family conflict. Role conflict theory, which is traditionally rooted in role theory, is among the most well known. Role theory suggests that individuals occupy a variety of roles on a daily basis. These roles may be inherently incompatible given that they comprise various time and behavioral expectations. Interrole conflict involves the clash between obligations. Individuals experience work-family conflict when attempting to simultaneously occupy or engage in both types of roles (Greenhaus \& Beutell, 1985; Kahn, Wolfe, Quinn, Snoek, \& Rosenthal, 1964).

Demand-resource models have also been used to explain the antecedents and processes of work-family conflict. These theories largely draw from Karasek's (1979) classic job-demand control model (for applications, see Laurijssen \& Gorieux, 2013). Demand-resource models suggest that the focal determinants of work-family conflict include the demands and resources at home and work (Bakker \& Geurts, 2004). For example, greater job pressures, work hours, or number of children may increase work-family conflict (Jacobs \& Gerson, 2004; Schieman et al., 2009). Similarly, greater work and family resources, such as work flex-time, schedule control, a supportive spouse, or paid domestic help, may decrease work-family conflict (Voydanoff, 2007). Demand-resource models closely parallel "scarcity" arguments, which emphasize the zero-sum nature of time: The more time spent in one activity or domain necessarily limits time available in other domains (see Greenhaus \& Beutell, 1985).

Recent research on the causes and consequences of work-family conflict among women advocates employing an institutional or organizational perspective compared to previous theories. This approach highlights the cultural and structural arrangements of individuals' lives, rather than framing work-family conflict as private, personal, or isolated matters (Hobson, 2014; Moen, 2015). Our approach is similar in that it assumes individuals are forced to make compromises or transitions as a result of institutional expectations or because of the absence of organizational supports. Contrary to a total structural approach, our framework assumes a level of agency among workers to transform their circumstances in the face of work-family adversity. The onus is therefore on individuals to make role changes precisely because of the structural lag in institutional and organizational supports across public and private spheres. The current study therefore speaks to recent calls to focus work-family scholarship on "... how workers actively strategize to maximize work-family balance" within institutional constraints (Bianchi \& Milkie, 2010, p. 715). This remains an understudied yet increasingly important phenomenon.

We limit our focus to particular work-related strategies that may help individuals cope with work-family challenges. Broadly, these strategies cohere around the following two typologies: (a) changes in work demands (i.e., work hours and job pressures) and (b) changes in job or workplace flexibility (Barnett \& Rivers, 1998; Becker \& Moen, 1999; Blair-Loy, 2003; Kaufman \& Uhlenberg, 2000). We first discuss literature on women's adoption of such strategies and then consider whether men implement similar strategies in the face of work-family conflict.

\section{Changes in Work Conditions}

A prominent work-related strategy that women may employ involves changing demanding work conditions in an attempt to reduce work-family conflict. Women may scale back on work hours or job pressures to allow them more time and energy to tend to family responsibilities (Carr, 2002; Maume, 2006). Research suggests that women do in fact modify their work conditions to accommodate family expectations (Becker \& Moen, 1999; Bianchi \& Raley, 2005; Kaufman \& Uhlenberg, 2000). These findings are best demonstrated by qualitative studies using small samples of women. For example, Blair-Loy's (2003) interviews with 81 top executive women found that some successfully negotiated scaling back on hours and job pressures, even reducing to part-time arrangements in certain cases. Among the 125 female lawyers that Epstein, Seron, Oglensky, and Saute (1999) interviewed, several reported reducing hours and caseload to tend to family-related obligations. Despite 
the fact that scaling back on hours is effective in reducing work-family conflict, the women in Blair-Loy's and Epstein's studies reported criticism from their colleagues for defying the work-devotion schema characteristic of the profession, suggesting that scaling back may come with unfavorable consequences for one's image as a genuinely committed "ideal worker" (also see Munsch, Ridgeway, \& Williams, 2014).

Some women are unable to reduce their work hours or job pressures for financial reasons and instead may try to negotiate more flexibility around how, when, and where work is performed. Flexibility therefore refers to greater schedule control over work hours and tasks. Research finds that women, especially mothers with young children, are likely to ask for more flexibility to help balance competing demands (Kelly et al., 2011). In some cases, greater flexibility at work can lead to the perception of more balance, yet whether this is the case is debated: Greater flexibility may reduce permeability between work and family borders, encouraging more crossover and conflict rather than less. For example, Schieman and Young (2010) found that control over one's schedule would be beneficial in reducing work-to-family conflict were it not for the additional multitasking behaviors that resulted. Greater work-family multitasking in turn led to greater conflict. However, flexible work schedules may provide mothers with greater control to accommodate children's rigid academic or extracurricular schedules as well as the odd family emergency that may arise (see Kelly et al., 2014; Kush \& Stroh, 1994). Greater flexibility over where and when work is conducted may also reduce time and strain-based demands of the job, allowing women to attend to family obligations (Bianchi et al., 2006). Thus, it may be that women are more likely to seek flexibility at work in an effort to balance competing role expectations.

Changes in job pressures, work hours, and schedule control appear to be among the most common strategies adopted by women in the attempt to abate work-family conflict. The question then becomes the following: Are men adopting similar strategies, especially given recent reports that men are experiencing levels of work-family conflict comparable to their female counterparts (Aumann et al., 2011; Nomaguchi, 2009; Young, 2015)? It may be that women's work-family conflict levels are starting to reflect those of men's as they take on a breadwinner role in the home comparable to that of their partners. These women may see their work-related obligations as more interdependent with their family roles, rather than completely separate or independent, which would reduce perceived work-family conflict (see Simon, 1995). Changing gender norms and expectations in work and family may also be transforming the reported experience of work-family conflict for women, whereby women are able to separate the two spheres more successfully, leading to reports of conflict more comparable with their male counterparts.

Alternatively, these patterns may reflect men's increased investment in the family domain in the past decade (Doucet, 2006; Gerson, 2010). Growing reports of work-family conflict among men imply that they too may be adopting strategies to deal with competing role expectations (Aumann et al., 2011; Nomaguchi, 2009). It is likely that men-similar to women-are changing their perception of how work and family spheres should interact. In the past, men perceived their means of contribution to the family sphere through their paid work as the primary breadwinner. The two spheres were therefore seen as compatible with one another, rather than conflictual (Glavin et al., 2011; Simon, 1995). However, as men become more involved in other household and child-care tasks beyond financial provision, time-, strain- and behavioral-based conflicts between work and family may ensue (Doucet, 2006). These changing dynamics surrounding the "involved father" may necessarily change the perception of work-family conflict for these men, where work obligations that keep men from their family commitments are far more salient than in the past (Aumann et al., 2011).

Although the reasons underlying the observed patterns of work-family conflict among men and women are important, our study is primarily concerned with whether men are negotiating their work situations, such as women have, in order to achieve balance given these shifting trends. Gender norms about work-family priorities shape men's adoption of common work-related strategies. The expectation that men would not adopt similar work-related strategies compared to women reflects a more traditional perspective of assumed gender domain roles. The expectation that they would, however, aligns with greater gender egalitarianism across work and family institutions. We 
discuss these two potential scenarios in the following sections.

\section{Traditional Gender Role Norms: Hegemonic Masculinity and Femininity}

According to traditional gender role norms, women should be more likely to change their work schedule or demands when compared with men. Women are perceived as primarily responsible for the domestic domain, whereas men are considered financial providers for the household (Christiansen \& Palkovitz, 2001; Ridgeway, 2011). We would therefore predict that women would scale back on their work hours, try to reduce job demands, seek flexible work arrangements, or compromise their future careers for the sake of the family.

From a traditional perspective, however, men should be less likely to make work-related compromises for the family. Instead, they may be more apt to scale back on, opt out of, or compromise family-related time and obligations to achieve better balance (Coltrane, 2004; Maume, 2006). Becker and Moen's (1999) findings from interviews with 100 middle-class couples in upstate New York demonstrate this process. In most cases, the work-family adaptive strategies of scaling back, placing limits, or choosing a job versus a career were gendered. Although it seemed mutual among the couple, women were more likely to compromise their careers for jobs or scale back on work-related tasks and demands when compared with their husbands. These results are echoed by Kaufman and Uhlenberg (2000), who report that fathers with more traditional gender attitudes were likely to work more, compared to those fathers without children, to fulfill what they saw as the "good provider" role (Christiansen \& Palkovitz, 2001). The discrepancy between these preferences and circumstances highlight the constraints placed on individuals' adoption of strategies to achieve work-family balance.

It is also unlikely that organizations provide men with more flexible, autonomous work conditions for the purposes of balancing family obligations. When compared with women, men request flexible work schedules less often (Fried, 1998; Kelly et al., 2011). Moreover, when they do, qualitative accounts suggest that men may not admit "their need for workplace flexibility is family related" (Brescoll, Glass, \& Sedlovskaya, 2013, p. 370; Gerson, 1995; Powell, 1999). As
Brescoll et al. (2013, p. 371) point out, "respondents often report that their use of flexibility policies would make their status as caregivers more visible and salient in the workplace, much to their disadvantage." Trepidation among fathers to seek out workplace flexibility for family reasons may stem from traditional images of the "ideal worker," who prioritizes the job above all else (Acker, 1990; Kmec et al., 2014). From this perspective, men might be less likely to seek out similar work-related strategies as women to better balance competing obligations.

\section{Egalitarian Trends and Changing Gender Role Expectations}

An alternative view suggests that men are likely to adopt similar strategies as women when negotiating work-family conflict. From this perspective, work and family institutions have evolved, becoming less gendered, thereby equalizing men's and women's associated expectations. Similar to women's “quiet revolution" in the workplace (Goldin, 2006), men have redefined their presence in the home in the past few decades. Evidence about "men who mother" (Doucet, 2006) and "intimate fatherhood" (Dermott, 2008) highlight a growing trend of family and domestic devotion among men in the $21 \mathrm{st}$ century. A number of U.S. studies suggest that the time fathers spend with children has doubled during the past half century. Married fathers now spend approximately 6.5 hours a week on child care, which is approximately 3 hours more than reported in the 1960s (Pew Research Center, 2011). In Canada, 20\% of fathers report that they are primarily responsible for a number of child-care tasks related to getting children ready and helping with homework (Marshall, 2011; Young et al., 2014).

Father's increased domestic participation and reports of work-family conflict suggest that they may adopt work-related strategies similar to women to balance competing obligations. Although limited, there exists some evidence of these trends. We can infer that a small proportion of men are scaling back on paid employment to tend to child-care obligations. The numbers of stay-at-home fathers has increased slightly in the past decade. In 2012, stay-at-home fathers represented $8 \%$ of U.S. families with children younger than age 15 . This figure is up from $3 \%$ in 2004 (Bureau of Labor Statistics, 2011). These numbers are increasing in Canada, too, where 
fathers account for $12 \%$ of all stay-at-home parents when compared with 4\% in 1986 (Statistics Canada, 2011). Yet it is unclear whether work-family conflict is contributing to men's reduction in paid work hours. Changes in work conditions are also happening among men: Qualitative studies on dual-earner couples find that some men make sacrifices to better balance work and family by scaling back on work hours and job pressures. However, adjustments to husbands' work conditions are limited when compared with their wives (Barnett \& Rivers, 1998; Becker \& Moen, 1999; for an exception, see Risman \& Johnson-Sumerford, 1998).

Based on these ideas and evidence, it is likely that gender norms and expectations will influence men's adoption of work-related strategies similar to those of women. We further suspect that conditions in the household will also influence both men's and women's pursuits of changing work conditions. Of particular importance would be the presence of young children at home. Both mothers and fathers with young children will experience more work-family conflict than their parent counterparts, and their adoption of work-related strategies to abate such conflict will likely depend on this condition. Parents with younger children may pursue different work-related strategies when compared with those with older children to help cope with demanding time, energy, and child care associated with younger children (Bianchi et al., 2006; Gornick \& Meyers, 2004). Parents with younger children might have few options but to reduce their work hours or job load, seek more family-friendly employment options, or opt out of paid work all together (Maume, 2006; Stone, 2007). For example, Becker and Moen (1999) found that couples with young children are more likely to scale back on work demands or place limits on the work encroaching on family time. Furthermore, because women are still responsible for the majority of child care (Bianchi et al., 2006; Family Work Institute, 2005), we suspect that younger children will have a greater impact on women's pursuit of work-related strategies when compared with men's (for similar findings, see Gornick \& Meyers, 2004).

\section{FORMAL HYPOTHESES}

Based on the theory and evidence cited previously, we propose three specific hypotheses. The first includes the following competing components: Hypothesis 1a, the traditional gender hypothesis, states that men do not adopt similar work-related strategies as women in response to work-family conflict; and Hypothesis $1 \mathrm{~b}$, the egalitarian gender hypothesis, states that men do adopt similar work-related strategies as women in response to work-family conflict. Hypothesis 2 states that men's and women's adoption of work-related strategies in response to work-family conflict will be greater among those with young children in the household.

\section{The Importance of FAmily Conditions}

It is important to note that decisions made in the workplace are often linked to family-related circumstances. The pursuit of greater schedule flexibility or reduced job demands is likely connected to compromises in the household or a spouse's work situation and domestic contribution. The presence of a stay-at-home spouse might alleviate conflict between competing domains as well as reduce the likelihood that respondents will cut back on work hours or job demands (Milkie \& Peltola, 1999; Moen \& Sweet, 2003). Because couples tend to be "decision making units"-meaning that decisions on behalf of one spouse are not made in isolation from the other (Becker \& Moen, 1999)—we consider a range of spouses' work and family characteristics.

We also account for the respondent's own family-related obligations and time commitments. Parents may be more or less likely to scale back on job demands or seek flexible work options depending on the distribution of household chores, time with children, family meals, or child care (Hosking \& Western, 2008). Parents' work-family conflict experiences also depend on these family-related factors (Michel, Kotrba, Mitchelson, Clark, \& Baltes, 2011). We account not only for baseline spouse- and family-related situations but also between wave changes in these circumstances to control for their impact on respondents' work-related strategies.

\section{MethoD \\ Sample}

We analyzed the Canadian Work, Stress and Health study, which involved telephone interviews with a national sample of working Canadians in 2011 (Wave 1) and 2013 (Wave 2). 
Our sampling frame included numbers from both landlines and cellular phones. Calls were made to a regionally stratified unclustered random probability sample generated by random-digit-dial methods, and interviews were conducted in English or French. The final sample was 6,004, with a response rate of approximately $40 \%$. Follow-up interviews with respondents were conducted 24 months after the initial interview, yielding a sample of 4,423 adults (74\% follow-up response rate).

We considered whether attrition rates impact our overall analyses by testing the probability of remaining across waves. We used probit regression analyses and regressed the likelihood of remaining in the sample at Wave 2 on all independent variables. From these predictions, we constructed the inverse mills ratio or the "hazard of attrition" (for additional details, see Klein \& Moeschberger, 2003). This ratio was then included as a control measure in all analyses to adjust for attrition as a result of work-related experiences and work-family conflict. In all models, this variable was nonsignificant. We are confident that attrition rates did not affect our final results.

The analytical sample includes married or cohabiting respondents with at least one child in the household at Wave 1. For our analyses, we excluded cases with missing values on the focal variables across both waves ( $n=610$ missing). We predicted the effect of work-family conflict on work-related strategies using a final sample of 474 mothers and 306 fathers.

\section{Dependent Measures}

Transitions in Job Demands. We considered the following two changing demands: job pressures and work hours.

Job pressure. At both waves, three items asked about the frequency in the past 3 months of the following: "Felt overwhelmed by how much you had to do at work?" "Have to work on too many tasks at the same time?" "The demands of your job exceeded the time you have to do the work?" Response choices are coded: "never" (1), "rarely" (2), "sometimes" (3), "often" (4), and "very often" (5). We averaged the items to create the index; higher scores indicated more job pressure (Carayon \& Zijlstra, 1999; Härmä, 2006; $\alpha=.85$, Wave $1 ; \alpha=.86$, Wave 2). We treated this variable as a continuous measure.
Work hours. At both waves, we asked respondents how many hours they work in a typical week.

Changes in work demands between waves. To measure changes in job pressures and work hours we generated deviation scores between Wave 1 and Wave 2 values. Our approach was similar to lagged dependent variable or dynamic modeling approaches other than we estimated the deviations prior to analyses.

Transitions in Work Flexibility. We used one measure to estimate transitions to more flexible schedules. At each wave respondents were asked one item about their schedule control: "Who usually decides when you start and finish work each day?" "Someone else" was coded 1, "you are able to decide within limits" was coded 2, and "you are entirely free to decide" was coded 3. Because this measure was ordinal in nature, we created a dichotomous deviation measure to reflect an increase in schedule control (1) across waves, compared to those who did not report increased schedule control between these time periods (0). This approach was more appropriate compared to using a continuous deviation score such as was done with work hours and job pressures.

\section{Independent Variables}

Work-to-family conflict at Wave 1. We used four items to measure work-family conflict adapted from the National Study of the Changing Workforce (Family Work Institute, 2005). The items asked participants how often in the past 3 months they had: "not had enough time for the important people in your life because of your job," "not have the energy to do things with the important people in your life because of your job," "work kept you from doing as good a job at home as you could," and "job kept you from concentrating on important things in your family life." Response choices are "very often" (1), "often" (2), "sometimes" (3), "rarely" (4), and "never" (5). We coded and averaged items so that higher scores reflected more work-family conflict $(\alpha=.90)$. We also tested family-to-work conflict in predicting our focal outcomes but did not find that this measure significantly predicted changes in work demands or schedule control. 
Presence of young children at Wave 1 . We measured the number of children residing in the household who were younger than 6 years of age (1) and compared these respondents to those whose children were aged 6 years or older (0). Recall that in our sample all respondents reported having at least one child at either wave. If respondents had a child(ren) younger than 6 and a child(ren) aged 6 years or older they still received a 1 on this variable. We initially tested differences between various ages of children $(<6,6-11,12-18)$. The only differences found were among those with children aged younger than 6 and those with children aged 6 years or older. These results parallel studies within the area that report that the presence of young children at home influences work-related strategies used to achieve balance (Becker \& Moen, 1999; Laurijssen \& Glorieux, 2013).

Number of children at home at Wave 1. We included a variable comprising the count of total number of children.

Change in children between waves. We created a deviation measure for the change in the number of children reported living in the household. Any deviation was coded 1 and compared to respondents who did not report changes in the number of children living in the household (0). We also included a dichotomous measure to capture whether the respondent had an infant in the household at Wave 1 (presence of child aged 2 or younger $=1$; no child aged 2 or younger $=0$, reference). We include a deviation measure for changes in the presence of an infant in the home between waves. Any deviation was coded 1 and compared to those with no deviation (0).

Confounding Family Conditions. For reasons previously discussed, we control for a variety of family conditions that may change across the two waves influencing reports of work-family conflict and adopted strategies to reduce such conflict.

Married (Wave 1). Individuals who were married were coded 1 compared to respondents who were cohabiting (0). All other respondents were excluded from analyses given our sample criteria. One's marital status may influence the adoption of work-related strategies to achieve balance. Married respondents may be more or less likely to come from dual-earning households compared to cohabiting respondents.
Moreover, married versus cohabiting respondents may experience work-family conflict differently (Michel et al., 2011).

Spouse work hours at Wave 1. We included a continuous measure for respondents' reports of their spouses' average work hours per week.

Spouse work-to-family conflict at Wave 1. We assessed participants' perceptions of their spouse's work-family conflict with an item that asks the following: "In the last three months, how often did your spouse's/partner's job interfere with home or family life." Response choices include "never" (1), "rarely" (2), "sometimes" (3), "often" (4), and "very often" (5; adapted from the 2008 National Survey of the Changing Workforce; for a review, see Aumann et al., 2010). Although single item measures of perceptions are not ideal, they have been used in previous research on crossover stress (Stevens, Kiger, \& Riley, 2006).

Frequency of chores and child care at Wave 1. We included separate measures of respondents' frequency of chores and child care. At both waves respondents were asked about the distribution of eight tasks between themselves and their spouse (Sweet, Bumpass, \& Call, 1988). These tasks included (a) preparing meals, (b) laundry, (c) cleaning house, (d) shopping for groceries, (e) dishes, (f) getting kids ready for school, (g) helping kids with homework, and (h) organizing family activities. Response choices included (1) "you always do it," (2) "you usually do it," (3) "both you and your spouse do it," (4) "your spouse usually does it," or (5) "your spouse always does it." These scores are summed and then averaged into two separate indices for chores and child care, where higher scores mean spouses perform more tasks ( $\alpha=.77$, Wave $1 ; \alpha=.76$, Wave 2 ).

Family meals. At each wave, respondents were asked how many nights per week their family eats a main meal together. Responses vary from 0 to 7 days per week.

Deviations in Spouse and Family Conditions Between Wave 1 and Wave 2. We created deviation scores between waves for the following variables: spouse's work hours, spouse's work-to-family conflict, distribution of chores and child care, and family meals per week. To create deviation scores we subtracted Wave 1 values from Wave 2 values and modeled these differences as continuous measures. 


\section{Social and Demographic \\ Covariates-Measures From Wave 1}

Gender. We used dummy codes for men (0) and women (1). Age was coded in years (22 to 59 years old for our subsample). Education contrasted "high school or GED" with "less than high school," "associate/2-year degree," "some college, no degree earned," "4-year university degree," or "graduate or professional degree (M.A./Ph.D.).” One item assessed personal earnings in the previous year from all sources with the following categories: " $\$ 25,000$ or less," "\$25,001 to $\$ 50,000$," " $\$ 50,001$ to $\$ 75,000$," "\$75,001 to $\$ 100,000, " “ \$ 100,001$ or more." We used $\$ 25,001$ to $\$ 50,000$ as the reference group.

We also controled for a variety of employment-related criteria, including occupation, employment type, and authority. These factors may influence respondents' ability to scale back on job demands or seek more flexible work options. For example, professionals are more likely to have schedule control but coupled with greater work demands. Similarly, self-employed respondents may have the ability to set their own schedules, compared to wage or salaried workers (Schieman, 2013; Schieman \& Young, 2010). We considered these potentially influential employment factors. To assess whether the participant was in a higher status occupation, the following question was asked: "What kind of work do you do? That is, what is your occupation?" Using the open-ended information provided, we coded higher status occupation ("executive" or "professional") with a category that combines all others ("technical," "service," "sales," "administrative" and "production"). We compared individuals who were "wage and salaried employees who work for someone else" with two other groups: "business owners with employees" and "independent self-employed without employees." We used the following three items to assess job authority: "Do you influence or set the rate of pay received by others?" "Do you have the authority to hire or fire others?" "Do you supervise or manage anyone as part of your job?" If the respondent reported "yes" to the last question, then we asked the following: "Do any of those individuals supervise or manage others?" We coded "no" responses as 0 and "yes" responses as 1 . To create the index, we summed these responses. These items were similar to those in other studies (Elliot \& Smith, 2004).
Change in employment status, position, or organization between waves. We assumed that individuals are actively making decisions to scale back on demands or seek flexible arrangements. However, it may be that individuals change job locations or position within the same organization (i.e., promotion, demotion). These lateral or vertical transitions may come with changes in one's schedule flexibility or work load. In an attempt to rule out causal variability, we considered whether respondents remained in the same job or position between waves when compared to all other scenarios. We created one variable to tap changes in job status or location. Respondents who remained working in the same job between waves were coded 1 and compared to those who said they had "stayed at same place of employment but changed positions" or "changed employment organizations" (0).

\section{Plan of Analysis}

To test our hypotheses we first ran a series of ordinary least squares regression models to predict the effect of work-family conflict at Wave 1 deviations in job demands. Table 2 (below) presents unstandardized regression coefficients for changes in job pressures (first two columns) as well as changes in work hours (final two columns). Negative coefficients signal a reduction in either outcome. In each case, we present the additive model and then test whether the effects of work-family conflict on changes in job demands vary for mothers and fathers by presence of young children (Female $\times$ Work-to-Family Conflict; Hypotheses 1a, 1b; Female $\times$ Work-to-Family Conflict $\times$ Child Younger Than 6, Hypothesis 2). Second, we followed a similar process predicting increased schedule control from work-family conflict (Table 3, below). For this outcome, we used binary logistic regression given the nature of our outcome and reported odds ratios across all models. Similar to the previous models, we tested two- and three-way interaction terms between gender, work-family conflict, and the presence of young children.

For all outcomes, we found significant three-way interaction terms between gender, work-family conflict, and the presence of young children (controlling for all lower order multiplicative and additive terms; see online Appendix 1). We limit our presentation of 
two-way interactions in the tables for the purposes of space, but report all other multiplicative coefficients in Appendix 1. We conducted subsequent Chow tests for significance across group slopes. These test statistics are presented below. The coefficients for each subgroup are presented in online Appendix 2.

\section{RESULTS}

Table 1 presents the descriptive statistics separately for mothers and fathers for all focal measures based on the reduced sample for our study. We used $t$ tests to determine gender differences in means and chi-square tests to determine differences in proportions for all binary variables. Consistent with recent findings, we did not observe gender differences in work-family conflict. Fathers worked more hours at Wave 1; mothers and fathers reported similar job pressures across waves, but fathers reported more schedule control generally across waves than mothers.

Table 2 presents ordinary least squares regression results for changes in job demands as outcomes, including deviations in pressures and hours between waves. Initially, findings indicate that work-family conflict reduces job pressures and work hours between waves (Model 1 in both panels; $b=-0.211, p<.001 ; b=-1.031$, $p<.05$, respectively). Subsequent models including interactions between our conflict measures and gender and gender and young children suggested that the effect of work-family conflict on deviations in job pressures and work hours varies for mothers and fathers with younger children when compared with those with older children $\quad\left(b_{\text {women } * \text { wfc*kidun6 }}=-.424, \quad p<.01\right.$; $b_{\text {women*wfc*kidun6 }}=-3.042, \quad p<.05, \quad$ respectively). These associations are best demonstrated visually. Figures 1 and 2 show a series of panels: Panel A of each figure presents results by gender for parents with younger children. Panel B of each figure presents results for parents without younger children in the household. In both cases, the dotted line represents fathers' results compared to mothers' results (solid black line). These graphs suggest that although both mothers and fathers with older children were likely to reduce job pressures and work hours (Panel $B$ in both Figures 1 and 2), mothers with young children were likely to scale back more because of work-family conflict when compared with fathers with young children who did not report a significant reduction in pressures or work hours. These results partially supported our hypotheses: Parents with younger children were more likely to reduce work demands; however, this may be more prevalent for mothers than fathers.

Table 3 presents binary logistic regression results for an increase in schedule control between waves. These results were similar to those previously reported in the opposite direction. Work-family conflict appears to increase the odds of increased schedule control in Model 1 (odds ratio $=1.199, p<.05$ ). However-similar to our previous findings for job demands - the impact of work-family conflict varied by gender and presence of young children. We present the relevant interaction terms in Model 3 (odds ratio $=2.361, p<.05$ ).

Our conditional associations for work-family conflict and increased schedule control are best demonstrated visually. Figure 3 shows the following two panels: Panel A presents results by gender for parents with younger children. Panel B presents results for parents without younger children in the household. In both cases, the dotted line represents fathers' results compared to mothers' results (solid black line). Fathers with older children were more likely to report increased schedule control as a result of work-family conflict between waves when compared with mothers with older children (Panel $\mathrm{B}$ in Figure 3). We observed divergent patterns for mothers and fathers with young children: These mothers were far more likely to report increased schedule control between waves when compared with fathers with young children, who-alternatively-were less likely to report increased schedule control at higher levels of work-family conflict (Panel A in Figure 3). Once again, these results collectively support our hypotheses: Parents with younger children were more likely to report increased schedule control as a consequence of work-to-family conflict; however, this may be more prevalent for mothers than fathers. These trends were opposite for parents with older children: These fathers were more likely than mothers to report increased schedule control because of work-family conflict. We discuss possible reasons for our findings in the following sections.

Subsequent Chow tests for significance between groups were conducted. Chow tests allowed us to test whether the slope for work-family conflict was the same across all 
Table 1. Descriptive Statistics for Study Variables for Mothers $(\mathrm{N}=474)$ and Fathers $(\mathrm{N}=306)$

\begin{tabular}{|c|c|c|c|c|}
\hline \multirow[b]{2}{*}{ Variable } & \multicolumn{2}{|c|}{ Mothers } & \multicolumn{2}{|c|}{ Fathers } \\
\hline & $M$ & $S D$ & $M$ & $S D$ \\
\hline \multicolumn{5}{|l|}{ Focal variables } \\
\hline Work-to-family conflict & 2.61 & 1.00 & 2.62 & 0.96 \\
\hline Job pressures & 3.09 & 1.11 & 3.15 & 1.04 \\
\hline Job pressures (Wave 2) & 3.11 & 1.02 & 3.09 & 1.07 \\
\hline Work hours & 35.36 & 12.36 & $44.70^{* * *}$ & 11.84 \\
\hline Work hours (Wave 2) & 35.22 & 11.19 & $44.07^{* * *}$ & 10.68 \\
\hline \multicolumn{5}{|l|}{ Schedule control } \\
\hline No control & 0.49 & - & $0.32^{* * *}$ & - \\
\hline No control (Wave 2) & 0.43 & - & $0.33^{* *}$ & - \\
\hline Some control & 0.37 & - & $0.51^{* * *}$ & \\
\hline Some control (Wave 2) & 0.45 & - & 0.51 & - \\
\hline Full control & 0.14 & - & 0.18 & \\
\hline Full control (Wave 2) & 0.12 & - & 0.17 & - \\
\hline \multicolumn{5}{|l|}{ Family covariates } \\
\hline Child younger than 6 years & .43 & - & 0.44 & - \\
\hline No. of children & 1.95 & 0.84 & 1.87 & 0.81 \\
\hline No. of children (Wave 2) & 1.90 & 0.85 & 1.86 & 0.77 \\
\hline Presence of infant & 0.21 & - & 0.11 & - \\
\hline Presence of infant (Wave 2) & 0.11 & - & 0.15 & - \\
\hline Married & 0.82 & - & 0.80 & - \\
\hline Spouse work hours & 44.92 & 10.02 & $36.00^{* * *}$ & 11.60 \\
\hline Spouse work hours (Wave 2) & 44.41 & 9.84 & 36.15 & 11.36 \\
\hline Spouse work-family conflict & 2.39 & 1.08 & $1.99^{* * *}$ & 0.99 \\
\hline Spouse work-family conflict (Wave 2) & 2.43 & 1.07 & 2.04 & 0.91 \\
\hline Frequency of chores ${ }^{\mathrm{a}}$ & 2.20 & .68 & $3.38^{* * * *}$ & 0.66 \\
\hline Frequency of chores $^{\mathrm{a}}$ (Wave 2) & 2.21 & .66 & 3.21 & 0.63 \\
\hline Frequency of child care ${ }^{\mathrm{a}}$ & 2.22 & .72 & $3.31^{* * *}$ & 0.70 \\
\hline Frequency of child care ${ }^{\mathrm{a}}$ (Wave 2) & 2.26 & .69 & 3.30 & 0.69 \\
\hline Family meals per week & 6.29 & 1.86 & 6.32 & 1.87 \\
\hline Family meals per week (Wave 2) & 5.06 & 1.87 & 5.09 & 1.90 \\
\hline \multicolumn{5}{|l|}{ Work covariates } \\
\hline Executive & 0.11 & - & $0.16^{*}$ & - \\
\hline Wage/salaried & 0.83 & - & 0.79 & - \\
\hline Owner & 0.06 & - & $0.10^{*}$ & - \\
\hline Self-employed & 0.11 & - & 0.11 & - \\
\hline Authority & 0.82 & 0.97 & 1.15 & 1.15 \\
\hline Same job between waves & 0.65 & - & 0.66 & - \\
\hline \multicolumn{5}{|l|}{ Social/demographic covariates } \\
\hline Age & 39.63 & 6.67 & $40.89^{* * *}$ & 6.65 \\
\hline Less than high school & 0.02 & - & 0.04 & - \\
\hline High school & 0.13 & - & 0.12 & - \\
\hline Some college & 0.08 & - & $0.14^{* *}$ & - \\
\hline Associate degree & 0.12 & - & 0.12 & - \\
\hline College degree & 0.47 & - & $0.40^{*}$ & - \\
\hline Graduate/professional degree & 0.18 & - & 0.18 & - \\
\hline$\$ 25,000$ or less & 0.22 & - & $0.05^{* * *}$ & - \\
\hline$\$ 25,001$ to $\$ 50,000$ & 0.41 & - & $0.32^{* * *}$ & - \\
\hline$\$ 50,001$ to $\$ 75,000$ & 0.22 & - & $0.26^{* * *}$ & - \\
\hline$\$ 75,001$ to $\$ 100,000$ & 0.10 & - & $0.20^{* * * *}$ & - \\
\hline More than $\$ 100,000$ & 0.05 & - & $0.05^{*}$ & - \\
\hline
\end{tabular}

Note. Asterisks signify significant differences between mothers and fathers within waves. We present means for continuous variables and percentages for categorical variables. We use $t$ tests to test gender differences across continuous variables and chi-square tests for all binary variables.

${ }^{\text {a }}$ Higher scores reflect that spouse performs more chores and child care when compared with the respondent.

${ }^{*} p<.05,{ }^{* *} p<.01,{ }^{* * *} p<.001$ (two-tailed test). 
Table 2. Ordinary Least Squares Regression of Changes in Work Conditions and Work-Family Conflict $(\mathrm{N}=780)$

\begin{tabular}{|c|c|c|c|c|}
\hline \multirow[b]{2}{*}{ Variable } & \multicolumn{2}{|c|}{ Change in Job Pressure } & \multicolumn{2}{|c|}{ Change in Work Hours } \\
\hline & (1) & (2) & (1) & (2) \\
\hline WFC & $-0.211^{* * *}$ & $-0.358^{* * *}$ & $-1.031^{*}$ & -1.921 \\
\hline Women & 0.110 & $0.990^{* *}$ & 0.168 & 6.478 \\
\hline \multicolumn{5}{|l|}{ Relevant interaction terms } \\
\hline Women $\times$ WFC & - & 0.114 & - & 0.849 \\
\hline Women $\times$ WFC $\times$ Child $<6$ Years $^{\text {a }}$ & - & $-0.424^{* *}$ & - & $-3.042^{*}$ \\
\hline \multicolumn{5}{|l|}{ Family covariates } \\
\hline Child younger than 6 years ${ }^{b}$ & -0.006 & $-1.100^{* *}$ & 1.772 & -2.267 \\
\hline No. of children & 0.056 & 0.059 & -0.205 & 0.179 \\
\hline$\Delta$ in no. of children & 0.044 & 0.043 & $-2.004^{*}$ & $-2.224^{*}$ \\
\hline Presence of infant & -0.014 & -0.013 & -2.195 & -2.027 \\
\hline$\Delta$ in presence of infant & 0.157 & 0.138 & 0.597 & 0.375 \\
\hline Married (vs. cohabiting) & -0.046 & -0.046 & -0.800 & 0.978 \\
\hline Spouse work hours & 0.001 & 0.001 & -0.041 & -0.050 \\
\hline$\Delta$ in spouse work hours & 0.001 & 0.001 & 0.001 & -0.001 \\
\hline Spouse WFC & -0.012 & -0.016 & 0.593 & 0.534 \\
\hline$\Delta$ in spouse WFC & -0.044 & -0.049 & -0.170 & -0.261 \\
\hline Frequency of chores & -0.036 & -0.030 & -0.744 & -0.689 \\
\hline$\Delta$ in frequency of chores & -0.028 & -0.045 & -0.581 & -0.646 \\
\hline Frequency of child care & 0.084 & 0.079 & 0.530 & 0.534 \\
\hline$\Delta$ in frequency of child care & 0.114 & 0.124 & $1.801^{*}$ & $1.824^{*}$ \\
\hline Family meals per week & 0.017 & 0.022 & -0.420 & -0.382 \\
\hline$\Delta$ in family meals per week & -0.037 & -0.039 & $-0.559^{*}$ & $-0.582^{*}$ \\
\hline \multicolumn{5}{|l|}{ Work covariates } \\
\hline Executive & 0.033 & 0.057 & 0.274 & 0.432 \\
\hline Owner ${ }^{c}$ & -0.184 & -0.243 & -0.897 & -3.183 \\
\hline Self-employed ${ }^{c}$ & 0.184 & 0.150 & 0.686 & -0.775 \\
\hline Authority & -0.030 & -0.038 & -0.527 & -0.627 \\
\hline Same job between waves ${ }^{\mathrm{d}}$ & 0.036 & 0.032 & 0.582 & 0.563 \\
\hline \multicolumn{5}{|l|}{ Social/demographic covariates } \\
\hline Age & -0.007 & -0.004 & -0.049 & 0.152 \\
\hline Less than high school ${ }^{\mathrm{e}}$ & 0.339 & 0.218 & 1.093 & -0.974 \\
\hline Some college $\mathrm{e}^{\mathrm{e}}$ & 0.078 & 0.036 & 1.681 & 1.340 \\
\hline Associate degree $\mathrm{e}^{\mathrm{e}}$ & 0.034 & 0.033 & -0.254 & 0.498 \\
\hline College degree $e^{e}$ & 0.088 & 0.091 & 1.595 & 3.066 \\
\hline Graduate/professional degree $\mathrm{e}^{\mathrm{e}}$ & -0.093 & -0.092 & 0.958 & 2.341 \\
\hline$\$ 25,000$ or less ${ }^{\mathrm{f}}$ & 0.131 & 0.098 & -1.310 & 2.176 \\
\hline$\$ 50,001$ to $\$ 75,000^{f}$ & 0.189 & 0.240 & -1.663 & 0.216 \\
\hline$\$ 75,001$ to $\$ 100,000^{f}$ & -0.077 & -0.005 & -0.086 & 1.630 \\
\hline More than $\$ 100,000^{\mathrm{f}}$ & 0.284 & $0.319^{*}$ & -1.228 & -1.008 \\
\hline Constant & .091 & 1.124 & 7.878 & 5.539 \\
\hline$R^{2}$ & .104 & .119 & .069 & .084 \\
\hline
\end{tabular}

Note. Unstandardized regression coefficients reported. All models control for the probability of attrition between waves and tested for the possibility of nonlinear age effects, none of which were found. WFC = work-to-family conflict. $\Delta$ refers to "change in" each respective variable.

${ }^{\mathrm{a}}$ Lower order terms are included in each interaction model and are presented in Appendix $1 .{ }^{\mathrm{b}}$ Compared to no presence of children aged younger than 6 years. ${ }^{\mathrm{c} C o m p a r e d ~ t o ~ w a g e ~ a n d ~ s a l a r i e d . ~}{ }^{\mathrm{d}}$ Compared to respondents who changed job location or position between waves. ${ }^{\mathrm{e}}$ Compared to high school degree or GED. ${ }^{\mathrm{f}}$ Compared to $\$ 25,001$ to $\$ 50,000$.

${ }^{*} p<.05,{ }^{* *} p<.01,{ }^{* * *} p<.001$ (two-tailed test). 
Figure i. Predicted Change in Job Pressures by Work-Family Conflict for Presence of Child Younger Than Age 6 (Panel A) and No Children Younger Than Age 6 (Panel B) by Gender. Panel A: Child Younger Than 6 ; Panel B: No Children Younger Than 6 Present.

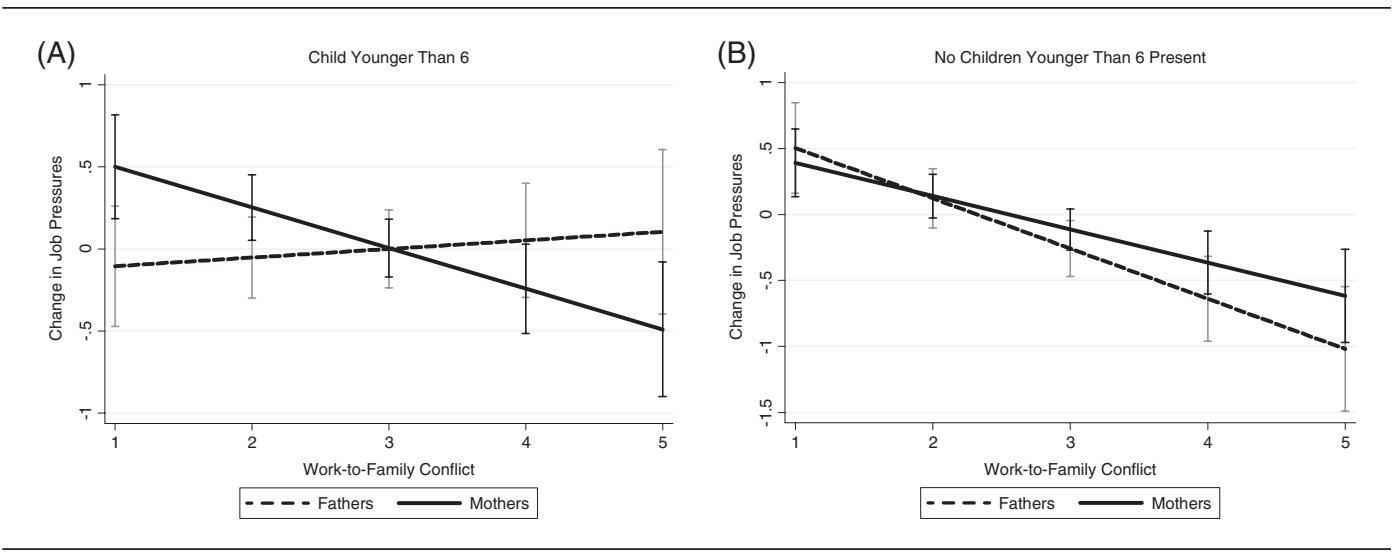

Note. Predicted values are based on Model 2 of "Change in Job Pressures" model series in Table 2. All continuous variables are held constant at their respective means. For categorical variables, we solved the equation for married mothers and fathers with a high school degree or GED, earning $\$ 25,001$ to 50,000 per year, nonexecutives/professionals, employed in private for-profit business. All continuous variables were set to their mean value.

Figure 2. Predicted Change in Work Hours by Work-Family Conflict for Presence of Child Younger Than Age 6 (Panel A) and No Children Younger Than Age 6 (Panel B) by Gender. Panel A: Child Younger Than 6 ; Panel B: No Children Younger Than 6 Present.
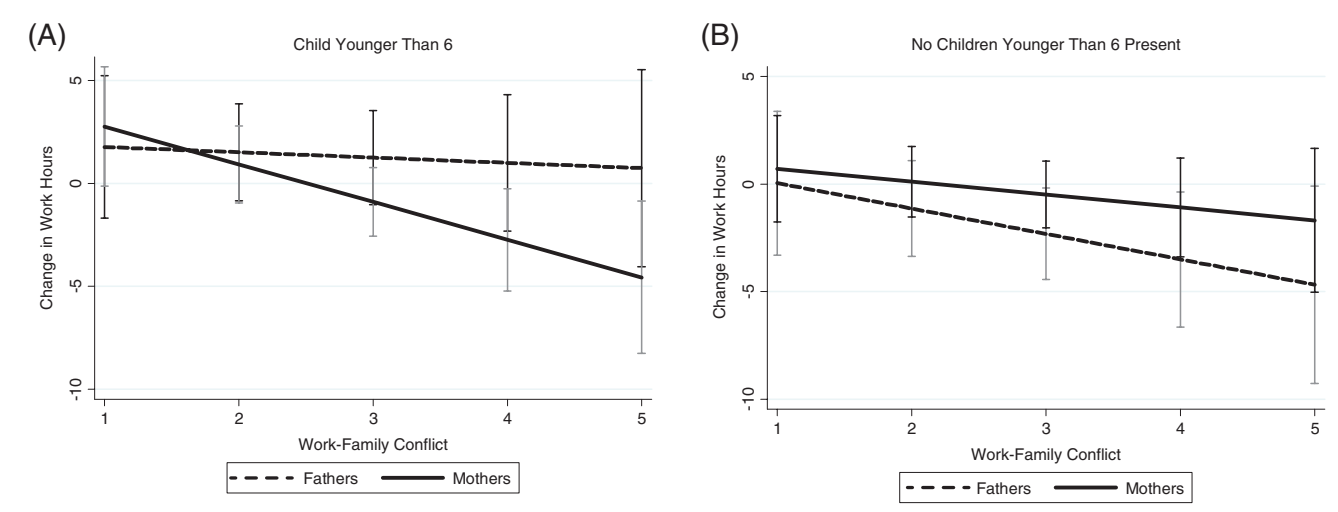

Note. Predicted values are based on Model 2 of "Change in Work Hours" model series in Table 2. All continuous variables are held constant at their respective means. For categorical variables, we solved the equation for married mothers and fathers with a high school degree or GED, earning $\$ 25,001$ to 50,000 per year, nonexecutives/professionals, employed in private for-profit business. All continuous variables were set to their mean value.

subgroups (i.e., women with and without young children; men with and without young children). For each outcome, we found that that the slopes did significantly vary ( $F_{\text {changejobpressures }}=2.30$, $\left.p<.05 ; \quad F_{\text {changeworkhours }}=2.20, \quad p=.05\right)$. We used the "test" statement in Stata to arrive at these values. The slopes used for each group to calculate these tests are presented in Appendix 2. We used a chi-square likelihood ratio test to examine differences for our third outcome-increased schedule control-because Chow tests can only be calculated for continuous outcomes and the latter measure is coded as binary. The likelihood ratio test was also statistically significant, suggesting differences in the effect of work-family conflict on increased schedule control across groups $\left(\chi^{2} \chi^{2}=4.11\right.$, $p<.05)$. 
Table 3. Binary Logistic Regression of Changes in Work Conditions and Work-Family Conflict $(\mathrm{N}=780)$

\begin{tabular}{|c|c|c|}
\hline \multirow[b]{2}{*}{ Variable } & \multicolumn{2}{|c|}{ Increase in schedule control } \\
\hline & (1) & (2) \\
\hline WFC & $1.199^{*}$ & $1.976^{* *}$ \\
\hline Women & 0.991 & 0.308 \\
\hline \multicolumn{3}{|l|}{ Relevant interaction terms } \\
\hline Women $\times$ WFC & - & $0.608^{*}$ \\
\hline Women $\times$ WFC $\times$ Child $<6$ Years ${ }^{\mathrm{a}}$ & - & $2.361^{*}$ \\
\hline \multicolumn{3}{|l|}{ Family covariates } \\
\hline Child younger than 6 years ${ }^{\mathrm{b}}$ & 0.796 & $6.016^{*}$ \\
\hline No. of children & 0.925 & 0.869 \\
\hline$\Delta$ in no. of children & 1.153 & 1.188 \\
\hline Presence of infant & 1.092 & 1.087 \\
\hline$\Delta$ in presence of infant & 0.950 & 0.979 \\
\hline Married (vs. cohabiting) & 1.038 & 0.769 \\
\hline Spouse work hours & 0.981 & 0.979 \\
\hline$\Delta$ in spouse work hours & 0.988 & 0.982 \\
\hline Spouse WFC & 0.911 & 0.988 \\
\hline$\Delta$ in spouse WFC & 0.998 & 0.922 \\
\hline Frequency of chores & 0.971 & 0.966 \\
\hline$\Delta$ in frequency of chores & 1.039 & 1.069 \\
\hline Frequency of child care & .942 & 0.937 \\
\hline$\Delta$ in frequency of child care & 1.014 & 0.995 \\
\hline Family meals per week & 0.940 & 0.928 \\
\hline$\Delta$ in family meals per week & 1.025 & 1.025 \\
\hline \multicolumn{3}{|l|}{ Work covariates } \\
\hline Executive & 1.006 & .984 \\
\hline Owner ${ }^{c}$ & .783 & 1.235 \\
\hline Self-employed ${ }^{c}$ & 1.134 & 1.494 \\
\hline Authority & 1.076 & 1.071 \\
\hline Same job between waves ${ }^{\mathrm{d}}$ & 1.001 & 1.024 \\
\hline \multicolumn{3}{|l|}{ Social/demographic covariates } \\
\hline Age & 0.989 & 0.953 \\
\hline Less than high school ${ }^{\mathrm{e}}$ & 0.376 & 0.517 \\
\hline Some college $\mathrm{e}^{\mathrm{e}}$ & 1.223 & 1.330 \\
\hline Associate degree $\mathrm{e}^{\mathrm{e}}$ & 1.086 & 0.936 \\
\hline College degree $e^{e}$ & 1.102 & 1.330 \\
\hline Graduate/professional degree $\mathrm{e}^{\mathrm{e}}$ & 1.623 & 1.296 \\
\hline$\$ 25,000$ or less ${ }^{\mathrm{f}}$ & 1.075 & 1.211 \\
\hline$\$ 50,001$ to $\$ 75,000^{\mathrm{f}}$ & 0.773 & 0.554 \\
\hline$\$ 75,001$ to $\$ 100,000^{\mathrm{f}}$ & 0.718 & 0.514 \\
\hline More than $\$ 100,000^{\mathrm{f}}$ & 0.624 & 0.579 \\
\hline Constant & 1.430 & .560 \\
\hline$\chi^{2}$ & 23.91 & 30.68 \\
\hline
\end{tabular}

Note. Odds ratios are reported. All models control for the probability of attrition between waves and are tested for the possibility of nonlinear age effects, none of which were found. WFC = work-to-family conflict. $\Delta$ refers to "change in" each respective variable.

${ }^{a}$ Lower order terms are included in each interaction model but not presented here. ${ }^{b}$ Compared to no presence of children younger than age $6 .{ }^{\mathrm{c} C}$ Compared to wage and salaried. ${ }^{\mathrm{d}}$ Compared to respondents who changed job location or position between waves. ${ }^{\mathrm{e}}$ Compared to high school degree or GED. ${ }^{\mathrm{f}}$ Compared to $\$ 25,001$ to $\$ 50,000$.

${ }^{*} p<.05,{ }^{* *} p<.01$ (two-tailed test). 
Figure 3. Predicted Increase in Schedule Control by Work-Family Conflict for Presence of Child under 6 (Panel A) and No Children under 6 (Panel B) By Gender. Panel A: Child Younger Than 6; Panel B: No Children Younger Than 6 Present.

(A)

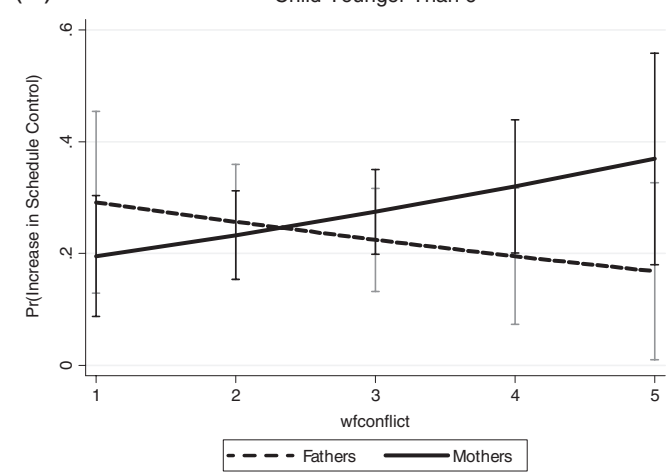

(B)

No Children Younger Than 6 Present

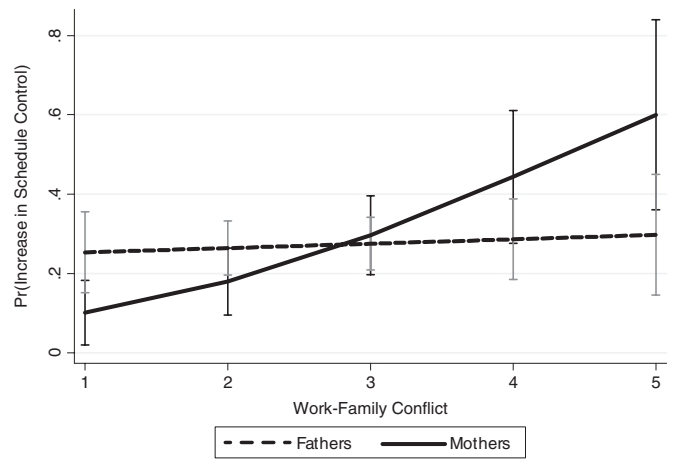

Note. Predicted values are based on Model 2 of "Increased Schedule Control" model series in Table 3. All continuous variables are held constant at their respective means. For categorical variables, we solved the equation for married mothers and fathers with a high school degree or GED, earning $\$ 25,001$ to 50,000 per year, nonexecutives/professionals, employed in private for-profit business. All continuous variables were set to their mean value.

\section{Family-Related Circumstances and Control Measures}

We documented several family, social, and demographic characteristics that influenced changes in work circumstances. An increase in number of children led to a decrease in work hours. Respondents whose spouses took on more child care reported working more hours at Wave 2. We did not find that our control measures impacted changes in schedule control.

\section{Discussion}

Our study discovers the answers to the following three questions: Does work-family conflict prompt individuals to modify their current work arrangements? Do mothers and fathers differ in the implementation of these strategies? Do our proposed associations between work-family conflict, gender, and work-related strategies depend on the presence of young children in the household? We advance prior scholarship by comparing men and women across occupations, rather than focusing on a select sample of women from one occupation. Although others have addressed this topic using representative European and British time use or social survey data, few have documented the association between work-family conflict and work-related strategies using Canadian data.
Our study addresses this gap and challenges the assumption that women are significantly different from men in adopting work-related strategies to help balance work and family. We examine the following strategies among mothers and fathers with and without young children at home: reducing job-related demands and finding more flexible work arrangements.

\section{Gender, Scaling Back, Finding Flexibility,} and the Household Presence of Young Children

We find that mothers with young children (aged younger than 6 years) are more likely to scale back on work demands and seek more schedule control compared to fathers with young children, who rarely report reducing demands because of work-family conflict. Across all three outcomes, the patterns are remarkably consistent. Combined, the results coincide with our traditional gender hypothesis: Women are perceived as primarily responsible for the domestic domain, whereas men are considered the financial providers for the household. It would therefore make sense that women scale back on their work hours, try to reduce job demands, or seek more flexible work arrangements, especially amidst the presence of young children. The fact that men do not scale back on paid work during the early years of their child's life suggests that these fathers may identify more with 
the "good provider" role when compared to later years (Kaufman \& Uhlenberg, 2000).

An alternate but related explanation suggests that young fathers may be eager to get ahead in their careers-investing heavily in their job duties in anticipation of greater rewards or promotional opportunities (Galinsky, Auuman, \& Bond, 2011). This is not to say young mothers do not desire the same career success, but they may be impeded by structural inequalities in the domestic sphere that require they take on the lion's share of child-care obligations-especially when children are young (Ridgeway, 2011; Williams, 2000). This of course assumes that parents with young children at home tend to be younger themselves, which coincides with life course expectations (George, 1999). Young fathers may also be hesitant to take on more flexible work arrangements despite the presence of young children at home. Recent studies document that although men are more likely than women to be afforded flexible options, they are less likely to take such advantage (Coltrane, Miller, DeHaan, \& Stewart, 2014). The "flexibility stigma" that follows men who use family-friendly options may have consequences for their career trajectories or promotion opportunities (Munsch et al., 2014). For similar reasons, Vandello, Hettinger, Bosson, and Siddiqi (2013) found that women are more likely to pursue flexibility options, even though both genders valued schedule control. Men who sought such conditions were deemed less masculine and less adherent to the traditional image of the "ideal worker" (Acker, 1990).

Our results may also reflect gendered patterns in organizational maternal or parental leave policies. Mothers and fathers of young children may be offered differential options for reduced or part-time work loads or alternate work arrangements. Traditional workplace cultures may assume that women-as primary caregivers - should have more access to reduced or flexible work. Up until recently, this was evident by the absence of paternal leave options in most workplaces, compared to maternity leave access (see Kamerman \& Moss, 2009). Nevertheless, a recent Canadian report finds that women with young children are less likely to use flexible work arrangements compared to any other group, suggesting that men might in fact have more access to these opportunities compared to their counterparts (Higgins et al., 2008).
The results for parents with children aged 6 years or older present intriguing patterns, specifically for fathers. Those with older children are actually more likely to report reduced hours, pressures, and increased flexibility as a result of work-family conflict when compared with mothers with similarly aged children and fathers with younger children. Such patterns may reflect stage of life: Older fathers are perhaps more established and have gained the experience necessary to feel secure scaling back on work demands or seeking flexible options. Research highlights that middle-aged workers are willing to pursue more favorable work conditions compared to other generations (Family Work Institute, 2005). In fact, some suggest this generation is "...responsible for creating the work/life balance concept" (American Management Association, 2014). These attitudes of entitlement or pursuit for balance may be different for the next generation, which has recently come to age in a competitive and somewhat precarious economic context (Family Work Institute, 2005; Kalleberg, 2009).

\section{Limitations and Conclusions}

Several limitations of our study are worth mentioning. First and foremost, we are unable to explicitly evaluate the influence of personal choice versus structural constraint. We attempt to do so by using two-wave panel data and theorizing "strategies" as those work-related changes that have been shown to effectively reduce work-family conflict. Moreover, our approach speaks to Bianchi and Milkie's (2010) call for researchers to extend greater agency to individuals in studies of work-family conflict. To assume solely that individuals are forced to change their job situation as a result of work-family conflict neglects individuals' active negotiation of stressors.

Second, we lack key measures that tap into why people decided to reduce job pressures or seek more flexible work schedules. Theoretically, we assert that work-family conflict influences these processes and find analytical evidence to support these claims. Qualitative data explicating this association would be ideal. Finally, although we use two-wave panel data, our results do not necessarily determine causal associations. We rely on preexisting theories and literature and analytically control for a variety of circumstances-including family circumstances 
and change in job position or location-to specify our associations between work-family conflict and changes in job conditions. Nevertheless, large scale, multiwave longitudinal data analyzed in a fixed-effects framework would be ideal.

Men's and women's experiences of work-family conflict are converging and so too are the work-related strategies they employ to deal with such conflict. Where it was once only women seen as scaling back on work demands or seeking out more flexibility, we now see men exhibiting similar behaviors-at least among those with school-aged children. Women with young children, however, are still more likely than fathers to scale back on work demands or seek flexibility because of work-family conflict, which speaks to the persistent gender inequality of paid and unpaid work roles - at least during the early years of children's lives. These finding have important theoretical implications for gender, work, and family scholarship as well as practical implications for employers who base hiring practices on stereotypes of gender differences in devotion toward work versus family.

\section{Note}

A grant award from the Canadian Institutes of Health Research supports this study (funding reference no. MOP-102730; Scott Schieman, P.I). We thank Paul Glavin for his helpful feedback.

\section{SUPPORTING INFORMATION}

Additional supporting information may be found in the online version of this article:

Appendix 1. Additional Interaction Terms from Multiplicative Regression Models in Tables 2 and 3

Appendix 2. Subgroup Slopes for Chow Tests for Significant Differences

\section{REFERENCES}

Acker, J. (1990). Hierarchies, jobs, bodies: a theory of gendered organizations. Gender \& Society, 4, 139-158. https://doi.org/10.1177/ 089124390004002002

Allen, T. D., \& Finkelstein, L. M. (2014). Work family conflict among members of full-time dual-earner couples: An examination of family life stage, gender, and age. Journal of Occupational Health Psychology, 19, 376-384. https://doi.org/10.1037/ a0036941

American Management Association. (2014). Leading the four generations at work. Retrieved from
http://www.amanet.org/training/articles/Leadingthe-Four-Generations-at-Work.aspx

Anxo, D., Mencarini, L., Pailhe, A., Solaz, A., Tantturri, M. L., \& Flood, L. (2011). Gender differences in time use over the life course in France, Italy, Sweden, and the US. Feminist Economics, 17, 159-195. https://doi.org/10. 1080/13545701.2011.582822

Aryee, S., Srinivas, E. S., \& Tan, H. H. (2005). Rhythms of life: Antecedents and outcomes of work-family balance in employed parents. Journal of Applied Psychology, 90, 132-146. https://doi.org/10.1037/0021-9010.90.1.132

Aumann, K., Galinsky, E., \& Matos, K. (2011). The new male mystique. Retrieved from http://familiesandwork.org/site/research/reports/ newmalemystique.pdf

Bakker, A. B., \& Geurts, S. A. (2004). Toward a dual-process model of work-home interference. Work \& Occupations, 31, 345-366. https://doi.org/ 10.1177/0730888404266349

Barnett, R. C., \& Rivers, C. (1998). She works, he works: How two income families are happy, healthy and thriving. Cambridge, MA: Harvard University Press.

Becker, P. E., \& Moen, P. (1999). Scaling back: Dual-earner couples' work-family strategies. Journal of Marriage and the Family, 61, 995-1007. https://doi.org/10.2307/354019

Bellavia, G. M., \& Frone, M. (2005). Work-family conflict. In J. E. Barling, K. Kelloway \& M. R. Frone (Eds.), Handbook of Work Stress (pp. 113-148). Thousand Oaks, CA: Sage.

Bianchi, S. M., \&. Milkie, M. A. (2010). Work and family research in the first decade of the 21st century. Journal of Marriage and Family, 72, 705-725. https://doi.org/10.1111/j. 1741-3737.2010.00726

Bianchi, S. M., \& Raley, S. B. (2005). Time allocation in families. In S. M. Bianchi, L. M. Casper, \& B. R. King (Eds.), Work, family, health, and well-being (pp. 21-42). Mahwah, NJ: Erlbaum.

Bianchi, S. M., Robinson, J., \& Milkie, M. A. (2006). The changing rhythm of American family life. New York: Russell Sage.

Bianchi, S. M., Sayer, L. C., Milkie, M. A., \& Robinson, J. P. (2012). Housework: Who did, does or will do it, and how much does it matter? Social Forces, 91, 55-63. https://doi.org/10.1093/sf/sos120

Blair-Loy, S. M. (2003). Competing devotions. Cambridge, MA: Harvard University Press.

Bond, J. C., Thompson, E. G., \& Prottas, D. (2003). Highlights of the 2002 national study of the changing workforce. New York: Families and Work Institute.

Brescoll, V. L., Glass, J., \& Sedlovskaya, A. (2013). Ask and ye shall receive? The dynamics of employer-provided flexible work options and the need for public policy. Journal of Social 
Issues, 69, 367-388. https://doi.org/10.1111/josi. 12019

Bureau of Labor Statistics. (2011). Labor market statistics from the Current Population Survey. Retrieved from http://www.bls.gov/cps/ lfcharacteristics.htm

Carayon, P., \& Zijlstra, F. (1999). Relationship between job control, work pressure and strain: Studies in the USA and The Netherlands. Work \& Stress, 13, 32-48. https://doi.org/10. 1080/026783799296174

Carr, D. (2002). The psychological consequences of work-family trade-offs for three cohorts of men and women. Social Psychology Quarterly, 65, 103-124. https://doi.org/10.1002/cd.210

Christiansen, S., \& Palkovitz, R. (2001). Providing as a form of paternal involvement: Why the good provider role still matters. Journal of Family Issues, 22, 84-106. https://doi.org/ $10.1177 / 019251301022001004$

Coltrane, S. (2004). Elite careers and family commitment: It's (still) about gender. The ANNALS of the American Academy of Political and Social Science, 596(1), 214-220. https://doi.org/10.1177/ 0002716204268776

Coltrane, S., Miller, E. C., DeHaan, T., \& Stewart, L. (2014). Fathers and the flexibility stigma. Journal of Social Issues, 69, 279-302. https://doi.org/10.1111/josi.12012

Connelly, R., \& Ghodsee, K. (2011). Professor mommy: Finding Work-family balance in academia. Maryland, DC: Rowman.

Craig, L., \& Mullan, K. (2010). Parenthood, gender and work-family time in the United States, Australia, Italy, France, and Denmark. Journal of Marriage and Family, 72, 1344-1361. https:// doi.org/10.1111/j.1741-3737.2010.00769

Dermott, E. (2008). Intimate fatherhood: A sociological analysis. Routledge: London.

Doucet, A. (2006). Do men mother? Fathering, care, and domestic responsibility. Toronto, Canada: University of Toronto Press.

Elliot, J. R., \& Smith, R. A. (2004). Race, gender, and workplace power. American Sociological Review, 69, 365-386. https://doi.org/10. $1177 / 000312240406900303$

England, P. (2010). The gender revolution: Uneven and stalled. Gender \& Society, 24, 149-166.

Epstein, C. F., Seron, C., Oglensky, B., \& Saute, R. (1999). The part-time paradox: Time norms, professional life, family, and gender. New York: Routledge.

Evans, E., \& Grant, C. (2008). Mama, PhD: Women write about motherhood and academic life. New York: Rutgers University Press.

Family Work Institute. (2005). Gender and generation. Retrieved from http://familiesandwork.org/ site/research/reports/genandgender.pdf
Fried, M. (1998). Taking time: Parental leave policy and corporate culture. Philadelphia: Temple University Press.

Galinsky, E., Aumann, K., \& Bond, J. T. (2011). Times are changing: Gender and generation at work and at home. Retrieved from http:// familiesandwork.org/site/research/reports/Times_ Are_Changing.pdf

George, L. K. (1999). Life course perspectives on mental health. In C. S. Aneshensel \& J. C. Phelan (Eds.), The handbook of the sociology of mental health (pp. 565-583). New York: Kluwer Academic.

Gerson, K. (1995). No man's land: Men's changing commitments to family and work. New York: Basic Books.

Gerson, K. (2010). The unfinished revolution: How a new generation is reshaping family, work, and gender in America. New York: Oxford University Press.

Glavin, P., Schieman, S., \& Reid, S. (2011). Boundary-spanning work demands and their consequences for guilt and psychological distress. Journal of Health and Social Behavior, 52, 43-57. https://doi.org/10.1177/0022146510395023

Goldin, C. (2006). The quiet revolution that transformed women's employment, education, and family. Cambridge, MA: National Bureau of Economic Research.

Gornick, J. C., \& Meyers, M. K. (2004). More alike than different: Re-assessing the long-term prospects for developing "European-style" workfamily policy in the United States. Journal of Comparative Policy Analysis: Research and Practice, 6, 251-273. https://doi.org/10. 1080/1387698042000305202

Greenhaus, J. H., \& Beutell, N. J. (1985). Sources of conflict between work and family roles. The Academy of Management Review, 101, 76-88. https://doi.org/10.5465/AMR.1985.4277352

Harmä, M. (2006). Work hours in relation to work stress, recovery and health. Scandinavian Journal of Work Environment Health, 32, 502-514.

Higgins, C., Duxbury, L., \& Lyons, S. (2008). Reducing work - life conflict: What works? What doesn't? Ottawa, ON: Health Canada.

Hobson, B. (2014). Work-life balance: The agency and capabilities gap. Oxford, UK: Oxford University Press.

Hosking, A., \& Western, M. (2008). The effects of non-standard employment on work-family conflict. Journal of Sociology, 44, 5-27. https:// doi.org/10.1177/1440783307085803

Jacobs, J. A. \& Gerson, K. (2004). The time divide: Work family and gender inequality. Cambridge: Harvard University Press.

Kahn, R. L., Wolfe, D. M., Quinn, R. P., Snoek, D., $\&$ Rosenthal, R. A. (1964). Organizational street: 
Studies in role conflict and ambiguity. New York: Wiley.

Kalleberg, A. L. (2009). Precarious work, insecure workers: Employment relations in transition. American Sociological Review, 74, 1-22. https://doi.org/10.1177/000312240907400101

Kamerman, S. B., \& Moss, P. (2009). The politics of parental leave policies: Children, parenting, gender and the labour market. Bristol, UK: Policy Press.

Karasek, R. A. (1979). Job demands, job decision latitude, and mental strain: Implications for job redesign. Administrative Science Quarterly, 24, 285-308. https://doi.org/10.2307/2392498

Kaufman, G., \& Uhlenberg, P. (2000). The influence of parenthood on the work effort of married men and women. Social Forces, 78, 931-949. https://doi.org/10.1093/sf/78.3.931

Kelly, E. L., Moen, P., \& Tranby, E. (2011). Changing workplaces to reduce work-family conflict: Schedule control in a white-collar organization. American Sociological Review, 76, 1-26. https://doi.org/ 10.1177/0003122411400056

Klein, J. P., \& Moeschberger, M. L. (2003). Survival analysis: Techniques for censored and truncated data (2nd ed.). New York: Springer.

Kmec, J. A., O'Connor, L., \& Schieman, S. (2014). Not ideal: the association between working anything but full time and perceived unfair treatment. Work and Occupations, 41, 63-85. https://doi.org/ $10.1177 / 0730888413515691$

Kush, K. S., \& Stroh, L. (1994). Flextime: Myth or reality? Business Horizons, 37, 51-55. https://doi.org/10.1002/ert.3910170406

Landivar, L. C. (2014). Opting out, scaling back, or business-as-usual? An occupational assessment of women's employment. Sociological Forum, 29, 189-214. https://doi.org/10.1111/socf.12075.189

Laurijssen, I., \& Gorieux, I. (2013). Career trajectories for women after childbirth: Job quality and work-family balance. European Sociological Review, 29, 426-436. https://doi.org/ 10.1093/esr/jcr08

Marshall, K. (2011). Paid and unpaid work over three generations. Perspectives on Labor and Income. Ontario, Canada: Statistics Canada.

Maume, D. J. (2006). Gender differences in restricting work efforts because of family responsibilities. Journal of Marriage and Family, 68, 859-869. https://doi.org/10.1111/j.1741-3737.2006.00300

Mennino, S. F., \& Brayfield, A. A. (2002). Job- family trade-offs: The multidimensional effects of gender. Work and Occupations, 29, 226 - 256. https://doi .org/10.1177/0730888402029002005

Michel, J. S., Kotrba, L. M., Mitchelson, J. K., Clark, M. A., \& Baltes, B. B. (2011). Antecedents of work-family conflict: A meta-analytic review. Journal of Organizational Behavior, 32, 689-725. https://doi.org/10.1002/job.695
Milkie, M., \& Peltola, P. (1999). Playing all the roles: Gender and the work-family balancing act. Journal of Marriage and the Family, 61, 476-490. https:// doi.org/10.2307/353763

Moen, P. (2015). An institutional/organizational turn: Getting to work-life quality and gender equity. Work \& Occupations, 42, 174-182. https://doi.org/10.1177/0730888414568085

Moen, P., \& Sweet, S. (2003). Time clocks: Couples' work hour strategies. In P. Moen (Ed.), It's about time: Career strains, strategies, and successes. Ithaca, NY: Cornell University Press.

Munsch, C. L., Ridgeway, C. L., \& Williams, J. C. (2014). Pluralistic ignorance and the flexibility bias: Understanding and mitigating flextime and flexplace bias at work. Work \& Occupations, 41, 40-62. https://doi.org/10. 1177/0730888413515894

Nomaguchi, K. M. (2009). Change in work-family conflict among employed parents between 1977 and 1997. Journal of Marriage and Family, 71, 15-32. https://doi.org/10.1111/j. 1741-3737.2008.00577

Pew Research Center. (2011). Five facts about today's fathers. Retrieved from http://www.pewresearch .org/fact-tank/2015/06/18/5-facts-about-todaysfathers/

Powell, G. N. (1999). Reflections on the glass ceiling: Recent trends and future prospects. In G. N. Powell (Ed.), Handbook of gender and work (pp. 325-46). Thousand Oaks, CA: Sage.

Reddick, R., Rochlen, A. B., Grasso, J. R., Reilly, E. D., \& Spikes, D. D. (2012). Academic fathers pursuing tenure: A qualitative study of work-family conflict, coping strategies, and departmental culture. Psychology of Men and Masculinity, 13, 1-15. https://doi.org/10.1037/a0023206

Ridgeway, C. L. (2011). Framed by gender: How gender inequality persists in the modern world. New York: Oxford University Press.

Risman, B. J., \& Johnson-Sumerford, D. (1998). Doing it fairly: A study of post-gender marriages. Journal of Marriage and the Family, 60, 23-40. https://doi.org/10.1177/0192513X14543852

Sayer, L. (2005). Gender, time and inequality: Trends in women's and men's paid work, unpaid work and free time. Social Forces, 84, 285-303. https://doi.org/10.1353/sof.2005.0126

Schieman, S. (2011). Canadian Work, Stress and Health Study. Funded by the Canadian Institutes of Health Research. Funding Reference: MOP-102730.

Schieman, S. (2013). Job-related resources and the pressures of working life. Social Science Research, 42, 271-282. https://doi.org/ 10.1016/j.ssresearch.2012.10.003

Schieman, S., Milkie, M. A., \& Glavin, P. (2009). When work interferes with life: work-non- work interference and the influence of work-related 
demands and resources. American Sociological Review, 74, 966-988. https://doi.org/10.1177/ 000312240907400606

Schieman, S., \& Young, M. (2010). Is there a downside to schedule control for the work-family interface? Journal of Family Issues, 31, 1391-1414. https://doi.org/10.1177/0192513X10361866

Simon, R. W. (1995). Gender, multiple roles, role meaning, and mental health. Journal of Health and Social Behavior, 36, 182-94. http://www.jstor.org/ stable/2137224

Slaughter, A. M. (2012, July/August). Why women still can't have it all. The Atlantic. Retrieved from http://www.theatlantic.com/magazine/archive/ 2012/07/why-women-still-cant-have-it-all/ 309020/

Spain, D., \& Bianchi, S. M. (1996). Balancing act. New York: Russell Sage.

Statistics Canada. (2011). Census of Canada: National Household Survey. Retrieved from http:// www12.statcan.gc.ca/census-recensement/indexeng.cfm

Stevens, D. P., Kiger, G., \& Riley, P. J. (2006). His, hers, or ours? Work-to-family spillover, crossover, and family cohesion. The Social Science Journal, 43, 425-436. https://doi.org/10.1016/ j.soscij.2006.04.011

Stone, P. (2007). Opting out? Why women really quit careers and head home. Berkeley: University of California Press.

Sweet, J., Bumpass, L., \& Call, V. (1988). The design and content of the National Survey of Families and Households (National Study of Families and Households working paper no. 1). Madison, WI: Center for Demography and Ecology, University of Wisconsin.

Sweezy, P., \& Jones, B. (2012). Women who opt out: The debate over working mothers and workfamily balance. New York: New York University Press.
U.S. Census Bureau. (2011). American Community Survey Public Use Microdata Sample. Retrieved from https://www.census.gov/newsroom/releases/ archives/american_community_survey_acs/cb12175.html

Vandello, J. A., Hettinger, V. E., Bosson, J. K., \& Siddiqi, J. (2013). When equal isn't really equal: The masculine dilemma of seeking work flexibility. Journal of Social Issues, 69, 303-321. https://doi.org/10.1111/josi.12016

Vanderweyer, J., \& Glorieux, I. (2008). Men taking up career leave: An opportunity for a better work and family life balance. Journal of Social Politics, 37, 271-294. https://doi. org/10.1017/S0047279407001742

Voydanoff, P. (2007). Work, family, and community: exploring interconnections. Mahwah, NJ: Routledge Publishing.

Wheaton, B., Young, M., Montazer, S., \& Stuart-Lahman, K. (2012). Social stress in the twenty-first century. In C. S. Aneshensel, J. C. Phelan, \& A. Bierman (Eds.), Handbook of the sociology of mental health, 2nd ed. (pp. 299-323). New York: Springer.

Williams, J. C. (2000). Unbending gender: Why family and work conflict and what to do about it. New York, NY: Oxford University Press.

Young, M. (2015). Work-family conflict in context: the impact of structural and perceived neighborhood disadvantage on work-family conflict. Social Science Research, 50, 311-327. https://doi.org/10 .1016/j.ssresearch.2014.12.001

Young, M., Schieman, S., \& Milkie, M. (2014). Spouse's work-to-family conflict, family stressors, and mental health among dual-earner mothers and fathers. Society \& Mental Health, 4, 1-20. https://doi.org/10.1177/2156869313504931 